\title{
Analysis on Collapse Prevention and Support for Bedding Borehole in Soft Coal
}

\author{
Shuren Wang ${ }^{1,2, *}$, Jingtao $\mathrm{Li}^{1}$, Dingqi $\mathrm{Li}^{1}$, Yubo Chen ${ }^{1}$ and Jiyun Zhang ${ }^{1}$ \\ ${ }^{1}$ International Joint Research Laboratory of Henan Province for Underground Space Development and Disaster Prevention, \\ Henan Polytechnic University, Jiaozuo 454003, China \\ ${ }^{2}$ School of Minerals and Energy Resources Engineering, University of New South Wales, Sydney, NSW 2052, Australia
}

Received 23 May 2021; Accepted 7 August 2021

\begin{abstract}
To solve the drilling hole collapse and plugging caused by the redistribution of stress in the coal after the shaping of the borehole, the collapse prevention support of bedding borehole was studied. Based on the attenuation characteristics of gas extraction concentration in the bedding borehole, the drilling mechanical model of surrounding rock was built to obtain the plastic solution of coal around the borehole. The computational model of the borehole collapse prevention and support in the form of borehole-screen pipe non-contact was established by using FLAC ${ }^{3 \mathrm{D}}$ to reveal the collapse pattern and support characteristics of the bedding borehole under different burial depths. Results show that the maximum tangential stress around the coal of the borehole is twice the original stress of the coal, and the maximum tangential stress determines the stability of the borehole. The stress is redistributed after drilling and forming, the coal shows the unloading effect, and the unloading range gradually increases with the increase of the burial depth. The deformation of the borehole wall increases with the increase of burial depth, indicating that the screen pipe provided good support stability to the borehole. The conclusions obtained in this study provide the reference to the gas extraction in soft coal.
\end{abstract}

Keywords: Soft coal, Bedding borehole, Collapse prevention, Numerical simulation

\section{Introduction}

With the development of coal mining industry, the amount of coal carbon resources is increasing day by day, and the mining depth of coal is increasing gradually [1-2]. According to the second coal resource forecast, the coal carbon with burial depth of $600 \mathrm{~m}$ occupies $26.8 \%$ of the total resources, while coal carbon with burial depth of 1500 $2000 \mathrm{~m}$ occupy $28.1 \%$ of the total resources. The coal is influenced by the burial depth and geological structure, and the deep loose coal has the characteristics of high stress, high gas content and slow gas desorption rate. At present, the problems of high gas and high ground stress have become the main bottlenecks restricting the safe and efficient production of mines.

Pre-pumping of gas from coal-bed boreholes is one of the main measures for the regional and localized outburst elimination [3-5]. Coal-bed gas pre-pumping through the bedding borehole can improve coal mining efficiency. The quality of hole formation in the bedding borehole determines the efficiency of gas extraction. After the soft coal drilling hole is formed, the stress concentration is formed around the drilling hole due to the stress redistribution, and the hole is unstable and collapses, which seriously affects the gas extraction. How to improve the stability of the bedding borehole, ensure the quality of the hole formation, and improve the efficiency of gas extraction is becoming an important issue.

To solve the problem of the bedding borehole support, this study establishes the numerical model of the coal-bed borehole without contact with the support screen tube through FLAC ${ }^{3 \mathrm{D}}$ software, using the change of ground stress

*E-mail address: w_sr88@163.com

ISSN: 1791-2377 @ 2021 School of Science, IHU. All rights reserved.

doi:10.25103/jestr.144.18 to show the burial depth of the coal. By comparing the change characteristics of the stress field, displacement field and plastic zone of the borehole and supporting screen tube under different burial depths, the borehole deformation and collapse is analyzed. It is found that the screen tube has a significant influence on maintaining the stability and ensuring the quality of the borehole, which is of important meaning to select the support method and improve the quality of the borehole.

\section{State of the art}

Gas as a by-product derived during the evolution of the coalbed, the gas is stored in the pores and fissures of coal in both free and adsorbed states [6]. During the mining coal, the methane is defined as a substance that endangers mineral safety. With the development of science and technology, the gas was redefined in the early 1980's and commercially developed and widely used as a clean energy source [7-8]. So, the gas stored in coal-bed has gradually become the focus of attention.

Many scholars have done the research improving gas collection rate. Xia et al. investigated the spontaneous combustion of coal with the variation law of gas and oxygen by developing a coupled model of mechanical deformation, gas flow and transmission, and heat transport of coal [9]. Tao et al. investigated the effect of the Klingberg effect on coal-bed methane by establishing a correlation model of coal permeability, and they found that the increase of effective stress caused by the decrease of gas pressure changed the porosity and permeability of coal [10]. Sun et al. developed a predictive drainage model and a gas desorption area model and found that when the gas desorption area expanded, the 


\section{Journal of Engineering Science and Technology Review 14 (4) (2021) 146 - 152}

early expansion rate of drainage area in the mining stage was greater than that in the later stage [11].

Pre-pumping of coal-bed gas by the bedding borehole can achieve the regional outburst elimination and reduce the risk of gas protrusion, therefore, it is crucial to study the anti-collapse support of the bedding borehole for safe mine production. Whittles et al. studied the variation law of shear stress of layer-through drilling according to different roof conditions, and they thought the poor stability of roof strata seriously affected the effective extraction time of gas [12]. Hashermi et al. verified the stability of drilling holes in cement poor sand layer and obtained the failure rules under different criteria [13]. Haimson obtained the micromechanical variation law of borehole deformation and collapse [14]. Steven et al. considered that the horizontal branch appearance layout form was beneficial to the stability of borehole [15]. Tezuka and Niitsuma proposed the stability rule and factors influencing the borehole based on elasticplastic and visco-elastic models [16].

Since the conditions of the borehole are more complex, there is a lack of analysis for the influence of stress environment, coal structure, and coal fractures on the stability of the borehole. Wang and Sun found that the active support applied on the hole wall could effectively prevent the extension of the plastic and damage zones around the borehole [17]. Zhang et al. proposed deformation models for intact, collapsed and plugged holes based on the creep deformation characteristics of the coal and the deformation mechanism of the boreholes [18]. Due to the anisotropy of the weak bedding plane in geological strata, the generated fracture region had great influence on the stability of drilling, which brought great challenges to the process of drilling hole and downhole operation [19]. When the coal seam was in under-equilibrium conditions, the initially stable borehole would collapse over time [20]. Papamichos investigated the damage pattern of the borehole and analyzed the effect of pore pressure on the stability of the borehole [21]. Meier et al. considered that the scale effect was an important factor leading to borehole collapse [22].

Selecting the appropriate protection pipe to place in the borehole can better solve the collapse of the borehole in the soft coal and improve the efficiency of gas extraction. Michael and Erez established the numerical model to study the real situation of the borehole in the collapsed section [23]. The low density of mud in mudstone coal could better inhibit the slumping and swelling of coal seam, so that the borehole could keep better stability [24]. It was found that the adopt of sprayed foam concrete slurry on the surface of the well wall could better reduce the collapse of boreholes in loose coal seams [25]. To support of the borehole could effectively reduce the collapse of the borehole, but increased the workload and cost.

It can be known in the secondary stress analysis of the deeply buried circular chamber, when the borehole and the screen pipe are in full close laminating, the screen pipe will provide active support force for the coal wall of the borehole, which changes the force state of the borehole coalbed in its natural form and violates the deformation damage criterion of the borehole. When using non-compact full contact form, the original force of the borehole coal-bed is maximum degree revivification, which more realistic response to the actual situation on site. This study established a numerical model of the borehole-screen pipe non-contact by FLAC ${ }^{3 \mathrm{D}}$ to analyze the variation characteristics of stress field, displacement field and plastic zone of the borehole as well as timbering screen pipe under different burial depths, and the anti-collapse support of bedding borehole was studied.

The rest of this study is organized as follows. Section 3 gives the relevant background and analysis methods. Section 4 describes the results and discussion, and finally, the conclusions are summarized in Section 5.

\section{Methodology}

\subsection{Engineering background}

The 1302 working face of $3^{\#}$ coal in Yuxi mine was used as the background, the average thickness of coal seam in the working face was $5.85 \mathrm{~m}$, and the average burial depth was $550 \mathrm{~m}$. The original gas pressure of $3^{\#}$ coal was $1.50-1.65$ $\mathrm{MPa}$, the adsorption constant $a$ was $42.84-43.10 \mathrm{~m}^{3} / \mathrm{t}$, and the adsorption constant $b$ was $1.196-1.221 \mathrm{MPa}^{-1}$. The original coal-bed gas content was $15.43-18.68 \mathrm{~m}^{3} / \mathrm{t}$, the initial velocity of gas diffusion $\Delta P$ was $25.20-27.80 \mathrm{ml} / \mathrm{s}$. The gas flow rate of the attenuation coefficient was average $0.044 \mathrm{~d}^{-1}$, which was belongs to the coal-bed that can be pumped.

Yuxi mine is a coal and gas herniated mine, and there is a risk of protrusion. At present, the biggest problem of gas extraction is the collapse and hole blocking of the bedding borehole. The gas extraction concentration is too low and the flow decay is too fast, which leads to the large gas content still existing in the coal-bed of the retrieval working face and low retrieval efficiency.

\subsection{Theoretical analysis}

As shown in Fig. 1, the destabilization of the hole wall of a coal-bed borehole is a shear damage that occurs because the strength of coal in hole wall is unable to meet the stress evolution demand. The coal is influenced by the original ground stress, and the stress around the borehole is redistributed to form the pressure relief area during the coalbed borehole forming process. By the disturbing effect of drilling tools, the pressure relief area is along the radial coal seam of the borehole to the deeper part ring form gradually expanding.

To simplify the stress distribution around the borehole, the following assumptions can be made:

1) The borehole is in the hydrostatic stress field with a lateral pressure coefficient of 1 .

2) The self-weight of the coal around the borehole is not counted, and the self-weight change caused by the excavation of the cavity is not considered.

3) The drilled holes are axisymmetric and regarded as the plane strain problems.

4) The coal-bed is uniformly and continuously isotropic, and the failure satisfies the Mohr-Coulomb criterion.

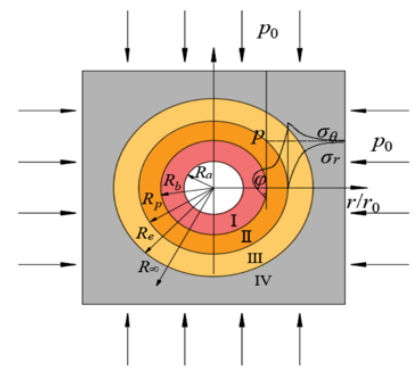

I-Crushing zone, II- Plastic zone, III-Elastic zone, and IV-Original stress zone. $R_{a}$-Radius of the borehole, $R_{b}$-Radius of the crushing zone, $R_{p}$-Radius of the plastic zone, $R_{e}$-Radius of the elastic zone, and $R_{\infty}$-Original coal-bed. Fig. 1. Stress distribution of coal-bed borehole. 
According to these assumptions, when in the plane strain state $\lambda=1$, the corresponding stress, strain and displacement solutions to the borehole are:

$$
\begin{aligned}
& \sigma_{r}=p_{0}\left(1-\frac{r_{a}^{2}}{r^{2}}\right) \\
& \sigma_{\theta}=p_{0}\left(1+\frac{r_{a}^{2}}{r^{2}}\right) \\
& \left.u=\frac{(1-\mu) p_{0}}{E}\left[(1-2 \mu) r+\frac{r_{a}^{2}}{r}\right]\right\} \\
& \varepsilon_{r}=\frac{(1+\mu) p_{0}}{E}\left[(1-2 \mu)-\frac{r_{a}^{2}}{r^{2}}\right] \\
& \left.\varepsilon_{\theta}=\frac{(1+\mu) p_{0}}{E}\left[(1-2 \mu)+\frac{r_{a}^{2}}{r^{2}}\right]\right]
\end{aligned}
$$

where, $\sigma_{r}$ is the radial stress, $\sigma_{\theta}$ is the tangential stress, $\varepsilon_{\theta}$ is the tangential strain, $\varepsilon_{r}$ is the radial strain, $E$ is the modulus of elasticity of coal-bed, $\mu$ is the poisson's ratio of the coalbed, $r$ is the distance from the center of the borehole, and $u$ is the radial displacement.

When the secondary stress of the drilling wall exceeds the yield stress of the coal, the coal of the hole wall will appear the plastic zone, which the coal is belong to the brittle material, and the yield stress usually adopts the MohrCoulomb linear strength as the basis for judging its into the plastic state, relying on the Mohr-Coulomb criterion to find the stress solution of each zone.

\subsubsection{Stress solution in the plastic zone}

The stress solution of the borehole in the plastic zone can be obtained:

$$
\begin{aligned}
& \sigma_{\theta}^{p}=\frac{\sigma_{c}}{A-1}\left[A\left(\frac{r}{R_{a}}\right)^{A-1}-1\right] \\
& \sigma_{r}^{p}=\frac{\sigma_{c}}{A-1}\left[\left(\frac{r}{R_{a}}\right)^{A-1}-1\right] \\
& R_{p}=r_{a}\left[\frac{2 p_{0}(A-1)+2 \sigma_{c}}{\sigma_{c}(A-1)}\right]^{\frac{1}{A-1}} \\
& u=r \varepsilon_{\theta}=\frac{2 R_{p}\left[p_{0}(A-1)+\sigma_{c}\right]\left(1+\mu_{0}\right)}{r E_{0}(A+1)}
\end{aligned}
$$

where, $\sigma_{\theta}^{p}$ is tangential stress in the plastic zone, $\sigma_{r}^{p}$ is radial stress in the plastic zone, plasticity conditions $A=\frac{1+\sin \varphi}{1-\sin \varphi}$, residual strength of coal-bed $\sigma_{c}=\frac{2 c \cos \varphi}{1-\sin \varphi}, c$ is cohesion of the coal-bed, $\varphi$ is friction angle of the coal-bed.

\subsubsection{Stress solution in the elastic zone}

The stress solution of the borehole in the elastic zone can be obtained:

$$
\left.\begin{array}{rl}
\sigma_{r}^{e} & =p_{0}\left(1-\frac{R_{P}^{2}}{r^{2}}\right)+\sigma_{R_{0}} \frac{R_{P}^{2}}{r^{2}} \\
\sigma_{\theta}^{e} & =p_{0}\left(1+\frac{R_{P}^{2}}{r^{2}}\right)-\sigma_{R_{0}} \frac{R_{P}{ }^{2}}{r^{2}} \\
u & =\frac{p_{0}(1+\mu)}{E}\left[(1-2 \mu) r+\frac{R_{p}^{2}}{r}\right] \\
& -\frac{(1+\mu) \sigma R_{P}^{2}}{E r}
\end{array}\right\}
$$

\subsubsection{Stress solution in the crushing zone}

When considering the boundary $r=r_{a}$, the tangential stress in the crushing zone is 0 . Therefore, combined with the equilibrium equation, the stress solution of the borehole in the crushing zone can be obtained:

$$
\left.\begin{array}{l}
\sigma_{\theta}^{b}=\frac{A \sigma_{c}}{A-1}\left[\left(\frac{r}{R_{a}}\right)^{A-1}-1\right]+\sigma_{C} \\
\sigma_{r}^{b}=\frac{\sigma_{c}}{A-1}\left[\left(\frac{r}{R_{a}}\right)^{A-1}\right]
\end{array}\right\}
$$

\subsection{Numerical simulation method}

\subsubsection{Building the model of coal-bed borehole}

Since the coal around the borehole has a great influence on the stability of the borehole, the Extrusion tensile tool in FLAC $^{3 \mathrm{D}}$ is adopt to establish the coal-rock mass model around the borehole, and this part of model mesh is adopt filling way to establish the irregular mesh of non-square shape [26-27]. Subsequently, adopting commands in FLAC $^{3 \mathrm{D}}$ to create the prototype library grid and to complete the establishment of the original coal around the borehole. The numerical model of the borehole is shown in Fig. 2.

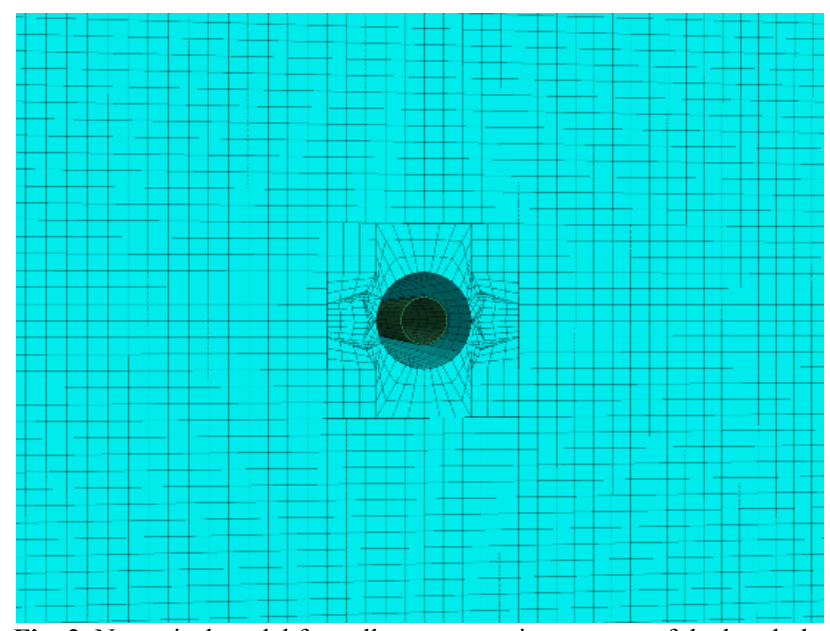

Fig. 2. Numerical model for collapse prevention support of the borehole

\subsubsection{Parameters of the numerical model}

To avoid the influence of the boundary effect on borehole stability, the model size is $2 \mathrm{~m} \times 2 \mathrm{~m} \times 2.5 \mathrm{~m}$, and the network model has 27000 units and 278562 nodes. Full constraint boundary conditions are used at the bottom of the model, the normal displacement constraints are used around the model, and the uniform load is applied to the top of the model in place of the self-weight of the overlying rock layer.

The model consists of two parts: the coal and the PVC timbering screen pipe, with a borehole diameter of $100 \mathrm{~mm}$. 
Shuren Wang, Jingtao Li, Dingqi Li, Yubo Chen and Jiyun Zhang/

Journal of Engineering Science and Technology Review 14 (4) (2021) 146 - 152

PVC screen pipe is adopted zone unit, and the screen pipe diameter is $50 \mathrm{~mm}$, with pipe wall thickness $2 \mathrm{~mm}$. The coal is defined as Mohr-Coulomb model and the PVC screen pipe is defined as Elastic model. By controlling the imposed load to characterized the borehole models at different burial depths, the lateral pressure coefficient is 1 for each calculated model. The calculation parameters are listed in Table 1.

Table. 1. Physical and mechanical parameters of coal and sieve tube.

\begin{tabular}{|c|c|c|c|c|c|c|}
\hline Name & $\begin{array}{c}\text { Unit weight } \\
\left(\mathrm{kN} / \mathrm{m}^{3}\right)\end{array}$ & $\begin{array}{c}\text { Elastic modulus } \\
(\mathrm{GPa})\end{array}$ & Poisson' ratio & $\begin{array}{c}\text { Cohesive strength } \\
(\mathrm{MPa})\end{array}$ & $\begin{array}{c}\text { Tensile strength } \\
(\mathrm{MPa})\end{array}$ & $\begin{array}{c}\text { Frictional angle } \\
\left({ }^{\circ}\right)\end{array}$ \\
\hline $\begin{array}{c}\text { Coal } \\
\text { Sieve tube }\end{array}$ & $\begin{array}{l}1.30 \\
1.38\end{array}$ & $\begin{array}{c}0.192 \\
3.20\end{array}$ & $\begin{array}{l}0.49 \\
0.32\end{array}$ & $\begin{array}{c}1.03 \\
-\end{array}$ & $\begin{array}{c}0.64 \\
-\end{array}$ & $\begin{array}{c}26 \\
-\end{array}$ \\
\hline
\end{tabular}

\section{Results and discussion}

\subsection{Stress solution to the coal-bed borehole}

The stress solution of coal around the borehole was proposed and the variation characteristics of plastic zone around the borehole under the influence of coal burial depth was obtained, as shown in Fig. 3. After shaping the coal-bed borehole, the stress of the surrounding coal of the borehole is redistributed. When the stress of the surrounding coal exceeds the yield stress of the coal-bed it will appear the plastic zone. The tangential stress of the coal around the borehole under different burial depths has the same decay trend, and the tangential stress of the coal decays gradually along the tangential direction from the borehole, and the maximum tangential stress is two times of the original stress.



Fig. 3. Tangential stress of the borehole with variation of distance.

The characteristic curve of radius distribution of the plastic zone of coal-bed borehole is shown in Fig. 4. According to the Mohr-Coulomb criterion, when the tangential stress is greater than the yield stress of the coal itself, the coal undergoes plastic damage, and the extent of the plastic zone at the coal-bed borehole is the main factor affecting the stability of the borehole. The radius of the plastic zone shows a tendency to growth approximately linearly with the initial stress. Therefore, with the increase of coal burial depth, the range of the plastic zone at the coalbed borehole is continuously extend, and the stability of the deep coal-bed borehole is worse.

\subsection{Stress characteristics of coal-bed borehole}

\subsubsection{Tangential stress analysis}

When the lateral stress coefficient of coal is 1 , definition maximum principal stress as the tangential stress, the second stress distribution of the borehole under different buried depths is shown in Fig. 5. The tangential stress gradually decreases progressively in the form of toroidal isoline from outside to inside, and the tangential stress around the borehole with the burial depth of $400 \mathrm{~m}$ shows a circularannular. For the burial depth of $600 \mathrm{~m}$ and $800 \mathrm{~m}$, the tangential stress presents the elliptical-annular.

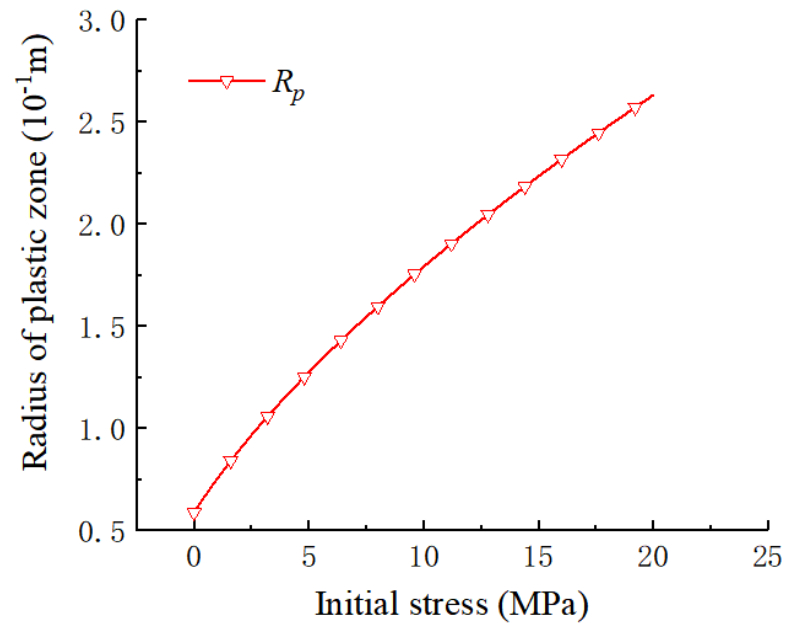

Fig. 4. Plastic zone of the borehole with variation of initial stress.



(a) Burial depth $400 \mathrm{~m}$

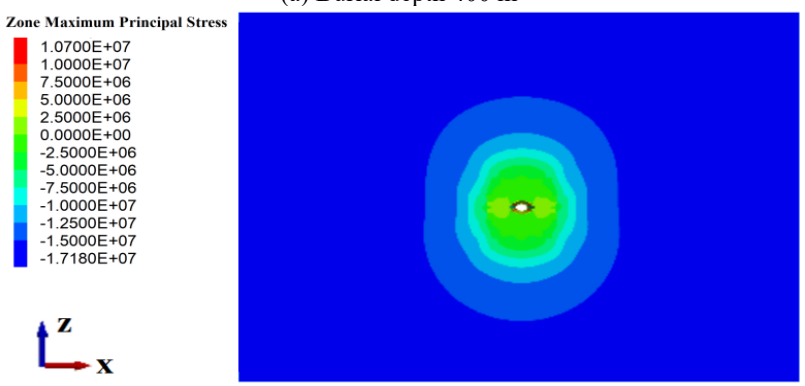

(b) Burial depth $600 \mathrm{~m}$

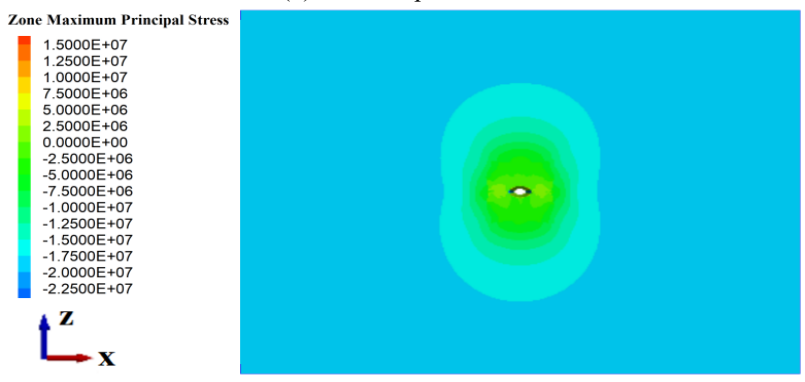

(c) Burial depth $800 \mathrm{~m}$

Fig. 5. Tangential stress distribution of the borehole. 


\subsubsection{Vertical stress analysis}

The middle position of the model working face is selected as the study object, and the cross section is at the position of $y=1.25 \mathrm{~m}$. Fig. 6 shows the vertical stress of the coal-bed borehole under different burial depths. When the lateral stress coefficient of coal is 1 , the stress around the borehole is symmetrically distributed in a "saddle shape", and the range of stress changes gradually diffusion outward in a "hat-shape". With the increase of buried depth, the range of stress relief area gradually increases. On the left and right sides of the borehole, there appears the stress elevate area, and the peak stress appears within a certain distance from the borehole wall.

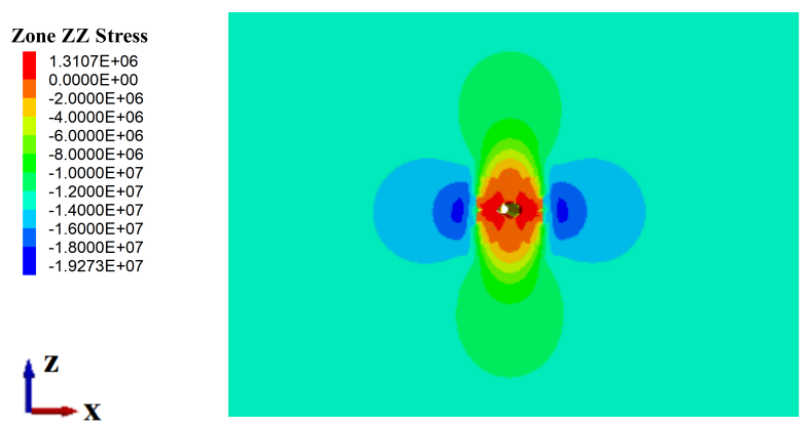

(a) Burial depth $400 \mathrm{~m}$

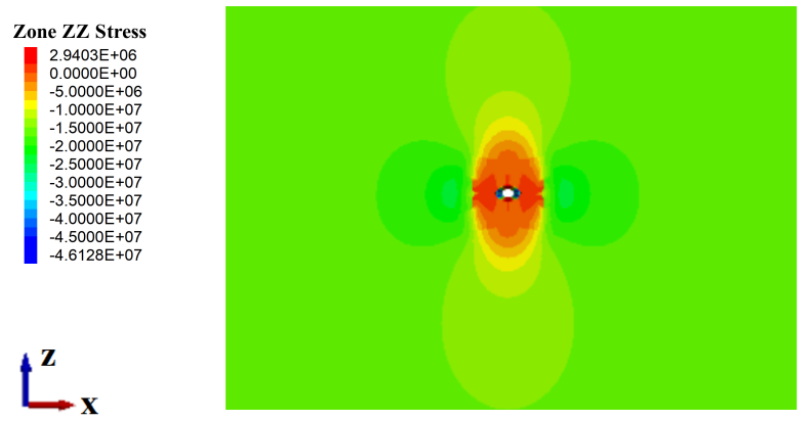

(b) Burial depth $600 \mathrm{~m}$
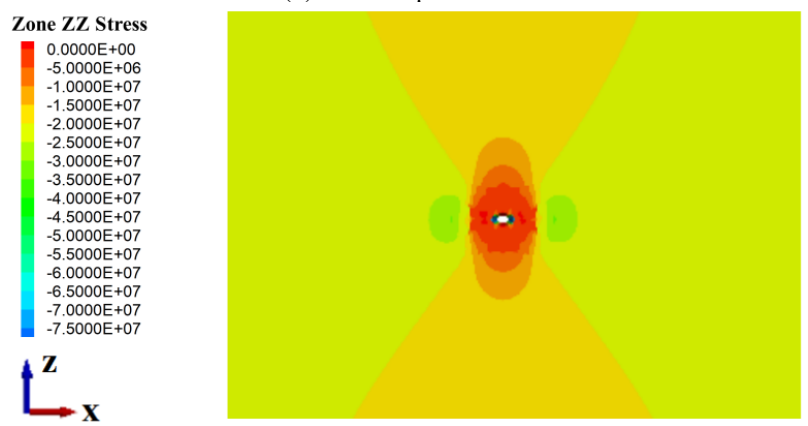

(c) Burial depth $800 \mathrm{~m}$

Fig. 6. Vertical stress distribution around the borehole.

Taking the center of the borehole as the origin, the vertical stress of the upper wall of the borehole and one point of the upper wall of the sieve pipe was respectively extracted for analysis, as shown in Fig. 7. The vertical stress of boreholes under different buried depths has the same decay trend. After the borehole being shaped, the stress decay of the borehole wall shows the state of unloading, the coal of the borehole wall is mainly subject to radial force, and the borehole is deformed with time under the action of stress. When the coal wall of the borehole is in contact with the screen pipe, the screen pipe will form a timbering effect on the borehole, and the force state of the coal of the borehole wall is changed at this time. As the timbering force provided by the screen pipe gradually increases, the force on the coal of the drill hole wall gradually tends to stabilize.

\subsection{Characteristics analysis of displacement}

Under the plastic state, the maximum displacement in the vertical direction of the borehole occurs at the wall of the borehole. The displacement of the coal gradually decreases in the form of "hump" to the deep part, as shown in Fig 8. The stress relief area forms around the borehole under hole cavern effect, the deformation of the upper hole wall is greater than that of the lower hole wall, and both displacements tend to move towards the horizontal middle axis wire of the borehole. With the increase of the burial depth, the displacement increases and the deformation of the screen pipe gradually tends to oval.

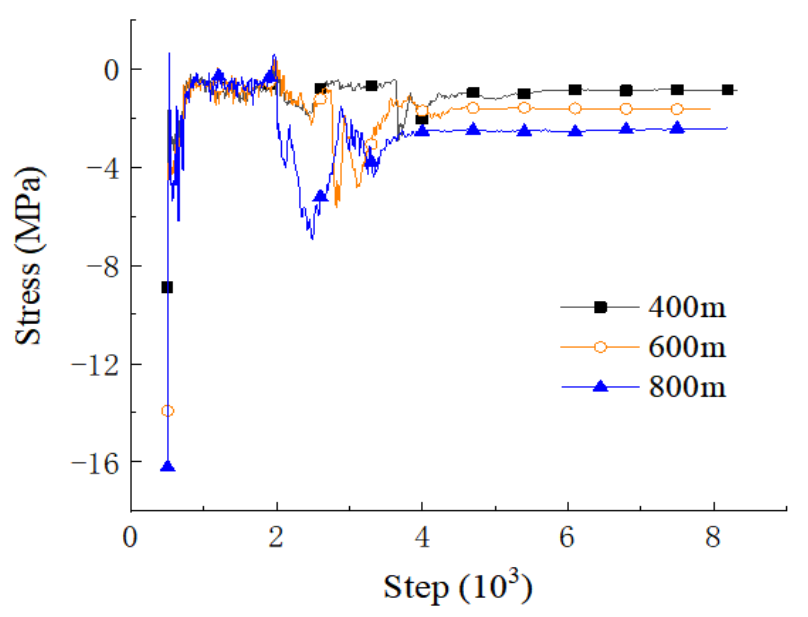

(a) Borehole upper wall



(b) Screen pipe upper wall

Fig. 7. Vertical stress distribution of the wall around the borehole.

As shown in Fig. 9, with the increase of the burial depth, the displacement of the borehole gradually increases and the maximum displacement of the upper wall of the borehole is $34 \mathrm{~mm}$. When the borehole is deformed to the contact between the hole wall and the screen pipe, the screen pipe starts to be deformed by the force and provides timbering force for the borehole. The displacement of the upper part of the screen pipe in the borehole with the burial depth of 800 $\mathrm{m}$ is $9 \mathrm{~mm}$. Both the borehole and the screen tube have large deformation in the early stage, and which gradually tends to stabilizes when satisfying the borehole timbering force. 
Shuren Wang, Jingtao Li, Dingqi Li, Yubo Chen and Jiyun Zhang/

Journal of Engineering Science and Technology Review 14 (4) (2021) 146 - 152



(a) Burial depth $400 \mathrm{~m}$

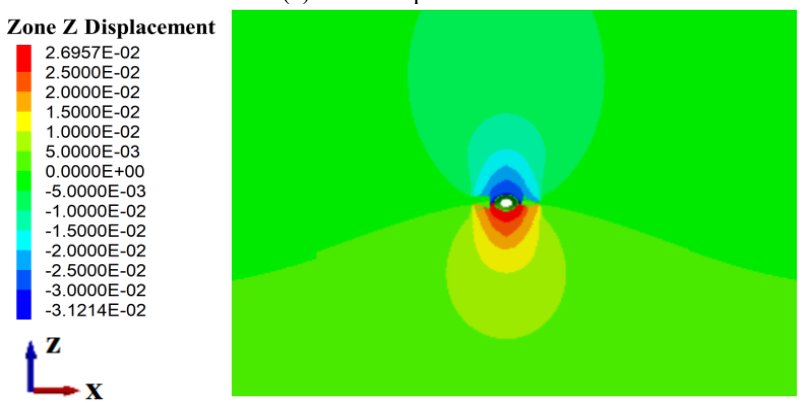

(b) Burial depth $600 \mathrm{~m}$

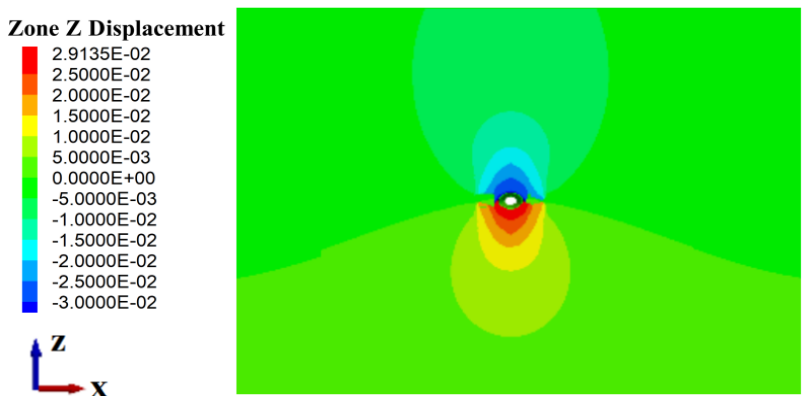

(c) Burial depth $800 \mathrm{~m}$

Fig. 8. Vertical displacement around the borehole.

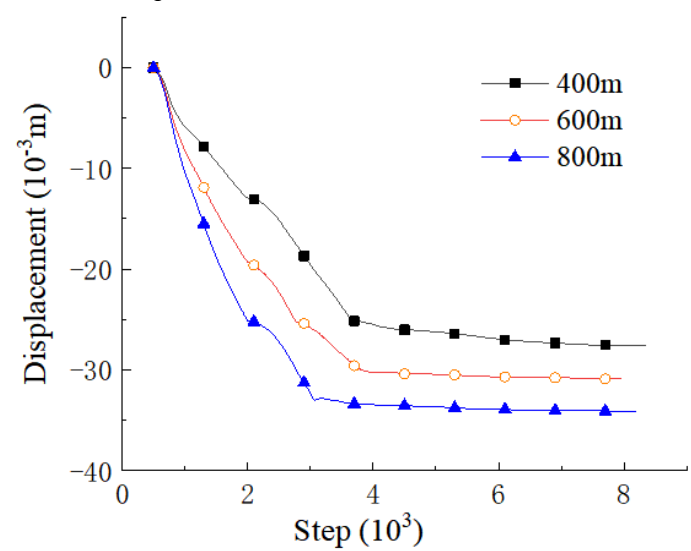

(a) Borehole upper wall



(b) Screen pipe upper wal

Fig. 9. Vertical displacement of the wall around the borehole.

\subsection{Characteristics analysis of plastic zone}

When the stress exceeds the yield stress of coal, the coal at the hole wall undergoes the plastic deformation. As shown in Fig. 10, the plastic state of the coal around the borehole is mainly divided into two kinds of elliptical area, inner and outer, they all are symmetrically distributed. The inner elliptical area takes the horizontal direction as the long axis, and the plastic state of coal is shear and tensile damage. The outer elliptical area takes the vertical direction as the long axis, and the plastic state of coal in this region is shear failure. The screen pipe is an elastic calculation model, and the vertical force of borehole deformation is greater than the lateral force, so the screen pipe undergoes elliptical deformation without plastic damage.



(a) Burial depth $400 \mathrm{~m}$

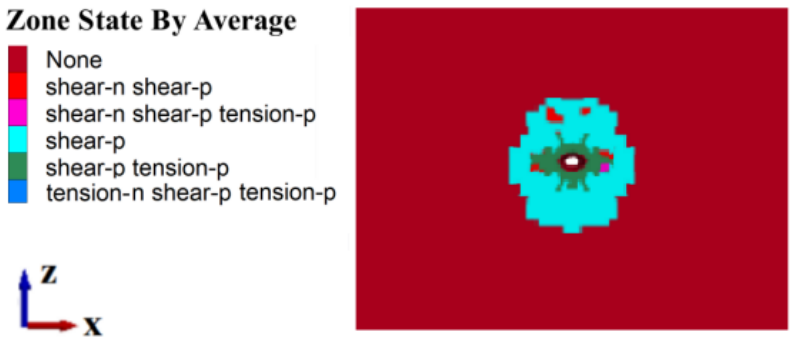

(b) Burial depth $600 \mathrm{~m}$

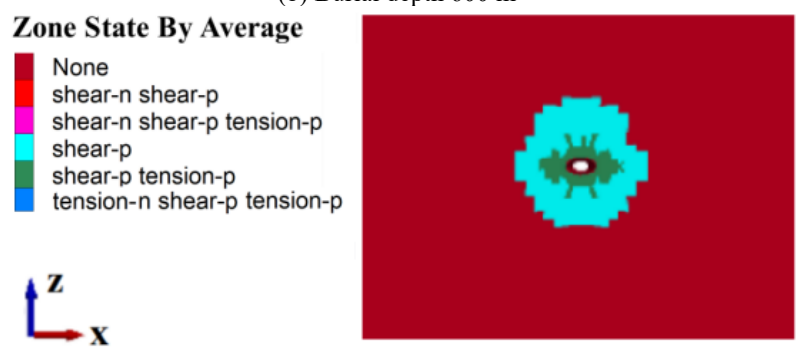

(c) Burial depth $800 \mathrm{~m}$

Fig. 10. Plastic zone distribution around the borehole.

\section{Conclusions}

Taking Yuxi coal mine as the engineering background, the numerical model of borehole anti-collapse support for soft coal was established. Combined with mechanical theory solutions to analyze the characteristics of borehole anticollapse support to reflect more realistic borehole collapse and timbering rules, the main conclusions are as follows:

(1) After the borehole shaping, the tangential stress gradually decreases progressively in the form of toroidal isoline from outside to inside. The vertical stress of the borehole is symmetrically distributed, and the range of stress relief increases with the increase of the buried depth.

(2) Hole collapse under the hole cavern effect occurs mainly in the vertical direction. The vertical displacement increases with the increase of the burial depth, which shows that the screen pipe can better maintenance the stability of the borehole. 
Shuren Wang, Jingtao Li, Dingqi Li, Yubo Chen and Jiyun Zhang/

\section{Journal of Engineering Science and Technology Review 14 (4) (2021) 146 - 152}

(3) The plastic zone of the coal around the borehole is mainly divided into two kinds of elliptical zones, inner and outer, all are symmetrically distributed. The inner elliptical area is mainly shear and tensile failure, while the outer elliptical area is mainly shear failure.

To maintain the stability of boreholes is crucial for the gas extraction. Since the actual shaping of the drilling hole is more complicated, the deformation stability of the borehole is need to be further studied.

\section{Acknowledgements}

This work was financially supported by the National Natural Science Foundation of China (51774112), and the Fundamental Research Funds for the Universities of Henan Province (NSFRF200202), China.

This is an Open Access article distributed under the terms of the Creative Commons Attribution License.

\section{References}

1. Zhao, Y. H., Wang, S. R., Zou, Y. F., Wang, X. C., Huang, B. Q., Zhang, X. G., "Pressure-arching characteristics of fractured strata structure during shallow horizontal coal mining". Technical Gazette, 25(5), 2018, pp. 1457-1466.

2. Wang, S. R., Li, N., Li, C. L., Zou, Z. S., Chang, X., "Instability mechanism analysis of pressure-arch in coal mining field under different seam dip angles". Dyna, 90(3), 2015, pp. 279-284.

3. Nima, N. D., Chen, Z. W., Saiied, M. A., Mehment, S. K., Pan, Z. J., Luke, K. C., "Impact of creep on the evolution of coal permeability and gas drainage performance". Journal of Natural Gas Science \& Engineering, 33, 2016, pp. 469-482.

4. Zhang, H. R., Lluis, S. P., Zhao, Y. J., Carla, V. S., "Researches and applications on geostatistical simulation and laboratory modeling of mine ventilation network and gas drainage zone". Process Safety and Environmental Protection, 94, 2015, pp. 55-64.

5. Wang, S. R., Li, N., Li, C. L., Hagan, P., "Mechanics evolution characteristics analysis of pressure-arch in fully-mechanized mining field". Journal of Engineering Science and Technology Review, 7(4), 2014, pp. 40-45.

6. Luke. D. C., Mazumder, S., Regina, S., Michale, C., Pan, Z. J., Deasy, H., "Laboratory characterisation of coal matrix shrinkage, cleat compressibility and the geomechanical properties determining reservoir permeability". Fuel, 165, 2016, pp. 499-512.

7. Tim, A. M., "Coalbed methane: A review". International Journal of Coal Geology, 101(1), 2012, pp. 36-81.

8. Alireza, K., Alexander, B., Themis, C., Pavel, B., Raymond, J. J., "Stimulation of coal seam permeability by micro-sized graded proppant placement using selective fluid properties". Fuel, 144, 2015, pp. 228-236.

9. Xia, T. Q., Zhou, F. B., Liu, J. S., Kang, J. H., Gao, F., "A fully coupled hydro-thermo-mechanical model for the spontaneous combustion of underground coal seams". Fuel, 125, 2014, pp. 106115.

10. Tao, Y. Q., Liu, D., Xu, J., Peng, S. J., Nie, W., "Investigation of the Klinkenberg effect on gas flow in coal matrices: A numerical study". Journal of Natural Gas Science \& Engineering, 30, 2016, pp. 237247.

11. Sun, Z., Li, X. F., Shi, J. T., Yu, P. L., Huang, L., Xia, J., Sun, F. R., Zhang, T., Feng. D., "A semi-analytical model for drainage and desorption area expansion during coal-bed methane production". Fuel, 204, 2017, pp. 214-226.

12. Whittles, D. N., Lowndes, I. S., Kingman, S. W., Yates, C., Jobling, S., "Influence of geotechnical factors on gas flow experienced in a UK longwall coal mine panel". International Journal of Rock Mechanics \& Mining Sciences, 43(3), 2006, pp. 369-387.

13. Hashemi, S. S., Taheri, A., Melkoumian, N., "Shear failure analysis of a shallow depth unsupported borehole drilled through poorly cemented granular rock". Engineering Geology, 183, 2014, pp. 39-52.
14. Haimson, B., "Micromechanisms of borehole instability leading to breakouts in rocks". International Journal of Rock Mechanics and Mining Sciences, 44(2), 2007, pp. 157-173.

15. Steven, A. K., Kramer, D. L., Michael, K., "A numerical study on optimization of multilateral horizontal wellbore patterns for coalbed methane production in Southern Shanxi Province, China". International Journal of Coal Geology, 86(4), 2011, pp. 306-317.

16. Tezuka, K., Niitsuma, H., "Stress estimated using microseismic clusters and its relationship to the fracture system of the Hijiori hot dry rock reservoir". Engineering Geology, 56(1-2), 2000, pp. 47-62.

17. Wang, Z. M., Sun, Y. N., "Swelling pressure of double-expansive material and its active support effect for coal seam gas drainage borehole". Advances in Materials Science and Engineering, 2018, 2018, pp. ID 8245036.

18. Zhang, X. B., Wang, W. Y., Yang. M., "Study on deformation and destabilization characteristics and modes of drainage borehole". Energy Sources, Part A: Recovery, Utilization, and Environmental Effects, 42(19), 2020, pp. 2448-2459.

19. Zhang, J. C., "Borehole stability analysis accounting for anisotropies in drilling to weak bedding planes". International Journal of Rock Mechanics \& Mining Sciences, 60, 2013, pp. 160-170.

20. Qu, P., Shen, R. C., Li, F. Z., Wang, J., "Time delay effect due to pore pressure changes and existence of cleats on borehole stability in coal seam". International Journal of Coal Geology, 85(2), 2011, pp. 212-218.

21. Papamichos, E., "Analysis of borehole failure modes and pore pressure effects". Computers \& Geotechnics, 37(1-2), 2010, pp. 141152.

22. Meier, T., Rybacki, E., Reinicke, A., Dresen, G., "Influence of borehole diameter on the formation of borehole breakouts in black shale". International Journal of Rock Mechanics \& Mining Sciences, 62, 2013, pp. 74-85.

23. Michael, E. B., Erez, N. A., "Methods for estimating pipe pullback loads for horizontal directional drilling (HDD) crossings". Journal of Infrastructure Systems, 8(1), 2002, pp. 12-19.

24. Yang, H., "Borehole stability in mudstone shale and coal seams in the Daniudi gas field". Chemistry \& Technology of Fuels \& Oils, 52(2), 2016, pp. 185-193.

25. Li, D. Q., "A new technology for the drilling of long boreholes for gas drainage in a soft coal seam". Journal of Petroleum Science \& Engineering, 137, 2016, pp. 107-112.

26. Wang, S. R., Zhao, J. Q., Wu, X. G., Yang, J. H., Liu, A., “Mesoscale simulations of lightweight aggregate concrete under impact loading”. International Journal of Simulation Modelling, 20(2), 2021, pp. 291-302.

27. Delić, Marko., Mandić, V., Popović, M., "Stability analysis of steel welded tubes forming process using numerical simulations". Technical Journal, 15(2), 2021, pp. 298-304. 